\title{
D2 Takım Çelik Üzerine Kaplanmış TiN Filmin Adezyon ve Yorulma Özelliklerinin Belirlenmesi
}

\author{
Ayşenur Keleş ${ }^{1 *}$ \\ ${ }^{1}$ Atatürk Üniversitesi Mühendislik Fakültesi Makine Mühendisliği Bölümü
}

Geliş / Received: 01/11/2019, Kabul / Accepted: 30/02/2020

\begin{abstract}
$\ddot{\mathbf{O} z}$
Takım malzemesinin işlenebilirliği o malzemenin çalışma ömrüne bağlıdır. Bu sebeple endüstride takım ömrünü artırmak için birçok işlem yapılmaktadır. Bunlardan en yaygın olanı malzemenin yüzeyini sert filmle kaplama işlemidir. Kaplanan filmin takım çeliğinin ömrünü artırabilmesi için taban malzeme ve film arasındaki adezyonun yüksek olması gerekmektedir. Sıçratma işlemi ile yapılan ince film kaplamalar, aşınma ve korozyon direncindeki gelişme, yüzey kalitesinin arttırılması, fonksiyonel özelliklerin zenginleştirilmesi ve kullanım ömrünün artması gibi üstün nitelikleri nedeniyle birçok endüstride yaygın olarak kullanılmaktadır. Bu çalışmada, D2 takım çeliğinin çalışma ömrünü artırmak için kaplanan TiN filmin adezyon ve yorulma ömrü incelenmiştir. TiN filmi $400^{\circ} \mathrm{C}$ taban malzeme sıcaklığında D2 takım çeliğinin üzerine sıçratma tekniği ile kaplanmıştır. Yapılan testler sonucu D2 çeliğine kaplanan TiN filminin ömrünün 1000 çevrimden daha fazla olduğu belirlenmiştir.
\end{abstract}

Anahtar Kelimeler: TiN, takım çeliği, adezyon, yorulma

\section{Determination of Adhesion and Fatigue Properties of TiN Film Coated on D2 Tool Steel}

\begin{abstract}
The machinability of the tool material depends on the working life. For this reason, many processes are performed in the industry to increase tool life. The most common of these is the surface coating process on the material with hard film. In order for the coated film to increase the life of the tool steel, the adhesion between the substrate and the film must be high level. Sputtering are widely used in many industries due to their superior qualities such as improved wear and corrosion resistance, improved surface quality, enhanced functional properties, and increased service life. In this study, the adhesion and fatigue life of TiN film coated to increase the working life of D2 tool steel was investigated. The TiN film was sputtered on tool steel D2 at $400{ }^{\circ} \mathrm{C}$ substrate temperature. As a result of the tests, the life of TiN film coated on D2 steel was determined to be more than 1000 cycles.
\end{abstract}

Keywords: TiN, tool steel, adhesion, fatigue

\section{Giriş}

Titanyum Nitrür (TiN) NaCl kaya tuzu kristal yap1s1 gösteren, düşük yoğunluğa ve yüksek erime noktasına sahip refrakter bir bileşiktir. Takım çelikleri için bir kaplama olarak TiN yaygın olarak kullanılmaktadır ve takım endüstrisinde büyük ilgi görmektedir (Zhang $\&$ Zhu, 1993). Bunun en önemli sebepleri, iyi adezyon, yüksek kimyasal dayanım, yüksek sıcaklıklara direnç, yüksek sertlik ve düşük sürtünme katsayısına $(\mu)$ sahip olmasıdır (Durusoy, Duyar, Aydınl1, \& Ay, 2003). TiN filmler yaygin olarak fiziksel buhar biriktirme 
(FBB) yöntemiyle, bu FBB yönteminden ise en yaygın sıçratma yöntemiyle kaplanmaktadır (Azadi, Sabour Rouhaghdam, \& Ahangaranic, 2016; Bhaduri, Ghosh, Gangopadhyay, \& Paul, 2010; Zhang \& Zhu, 1993).

Herhangi bir film biriktirme işleminde en önemli kaplama değişkenlerinden biri taban malzeme sicaklığıdır. Taban malzeme sıcaklığını kontrol etme kabiliyeti, biriktirme oran1, mikroyap1 ve üretilen kaplamanın özellikleri üzerinde büyük etkiye sahip olabilmektedir (Ghobadi, Ganji, Luna, Arman, \& Ahmadpourian, 2015; Patsalas, Charitidis, \& Logothetidis, 2000). Taban malzeme sıcaklığına göre en önemli nokta, elde edilen sonuçta ortaya çıkan mikroyapı ile doğrudan korelasyon göstermesidir. Örneğin, eğer taban malzeme oda sıcaklığındaysa, elde edilen mikroyapı biriktirme için kullanılan taban malzeme ile uyumlu olacaktır. Thornton tarafindan önerilen Yap1 Bölge Modeline (SZM) göre, yüzey atomlarının hareketliliği taban malzeme sıcaklığında artış olduğunda artar, bu da Bölge T'nin (geçiş bölgesi) oluşumuna yol açar. Biriktirme sırasındaki sıcaklığın artmasıyla, bölge 1, bölge T, bölge 2 ve bölge 3 gibi bölgelerin oluşumuna yol açar. Bu nedenle, genel olarak sıçratma işlemi sırasında, taban malzeme yüzeyindeki kimyasal reaksiyon ve yüzey atomunun hareketliliği taban malzeme sıcaklığından etkilenebilir. İnce film kaplama esnasinda taban malzemeye yüksek sicaklık kullanmanın avantajlarından biri, kaplamada üretilen kalıcı iç gerilmenin minimuma indirilmiş olmasıdır. Ayrıca, taban malzeme sıcaklığı, kaplama oranını önemli ölçüde etkilemektedir (Ohring, 2001; Thornton, 1988).

Tanecik yapısı, küçük boyutlu tanecikler daha yuvarlatılmış hale geldiğinden, tane boyutunda gözlenen yüksek sicaklık nedeniyle büyük ölçüde modifiye edilir. İnce filmin yüksek taban malzeme sıcaklığına sahip pürüzlülüğü, kullanılan tane boyutu elemanının yapısına bağlı olarak artabilir veya azalabilir. Kaya, S. ve arkadaşları, taban malzeme sıcaklığı değiştirildiğinde, yüzey pürüzlülüğü değeri, iletkenlik ve tane sınırının değiştiğini açıklamışlardır (Kaya, Yilmaz, Karacali, Cetinkaya, \& Aktag, 2015). X.-Y. Li ve ark., ince film biriktirme sirasında ortaya çıkan kalıcı iç gerilmenin taban malzeme sıcaklığındaki artış nedeniyle hızla azaldığını öne sürmektedir. Kaplanan tanelerin büyüme hızı ve ad atom hareketliliği, taban malzeme sıcaklığındaki artışa bağlı olarak artar. Ad atom hareketliliğindeki bu artış, biriktirilmiş filmlerin yüzey pürüzlülüğü özelliğini azaltır. Genel olarak, sıçratma işleminde daha iyi kristal elde etmek için, biriken atomların çok yüksek enerjiye sahip olmaları beklenir, bu önkoşul, yüksek taban malzeme sıcaklığının kullanımı ile yerine getirilir ( $\mathrm{Li}$ et al., 2009). Sun ve arkadaşlarına göre, taban malzeme sıcaklığı arttıkça, atom hareketliliğinde artış ve yapisal kusurlarda azalma ile sonuçlanacaktır (Sun et al., 2019). Ayrıca, sıçratma işleminde taban malzeme sıcaklığ1 arttıkça, daha düşük kusurlu ve daha yoğun filmler biriktirilir. İnce filmin direnci, başlangıçta taban malzeme sıcaklığı arttıkça düşer, ancak sıcaklık daha da arttığında, direnç arttırılır. Literatür çalışmaları incelendiğinde, malzemelerin adezyon değerlerinin ise $400-500{ }^{\circ} \mathrm{C}$ taban malzeme sıcaklığına kadar önemli oranda arttığı fakat sonrasında azalma meydana geldiği gözlemlenmiştir.

$\mathrm{Bu}$ sebeple bu çalışmada takım malzemelerinin ömrünü artıran TiN film, $400^{\circ} \mathrm{C}$ taban malzeme sicaklığında manyetik alanda sıçratma yöntemiyle D2 takım çeliği üzerine kaplandi. Kaplanan filmin 
mikroyapısal özelliği ve film kalınlığı SEM cihazı, kristalografik yönlenmesi XRD ile ve adezyon ve yorulma özellikleri ise sırasıyla çizik ve çoklu çizik testi ile gerçekleştirildi.

\section{Materyal ve Metot}

Takım malzemelerinin yorulma ömrünü belirlemek için taban malzeme olarak yüksek karbon ve krom içeren, 1 sıl işlem sırasında ise herhangi distorsiyona uğramayan ve takım aletlerinde yaygın kullanılan D2 takım çeliği seçildi. D2 takım çeliğinin kimyasal kompozisyonu Tablo 1'de verilmiştir. Taban malzemeye kaplama öncesi herhangi bir işlem yapılmamıştır. D2 takım çeliğinin ömrünü artırmak için kaplanan TiN film manyetik alanda sıçratma tekniği ile kaplandı. Kaplama anında bir adet Ti (\%99,99 saflıkta) hedef kullanıldı. Kaplamada iyonizasyonu sağlamak için Ar gazı, nitrür fazı elde edebilmek içinde $\mathrm{N}_{2}$ gazı kullanıld1. Kaplama öncesi taban malzeme ile film arasındaki adezyonu iyileştirmek ve kontaminasyonu azaltmak için taban malzemelere iyon temizleme yapildı. İyon temizleme $-850 \mathrm{~V}$ taban malzeme gerilimde $0.26 \mathrm{~Pa}$ çalışma basıncı altında $30 \mathrm{dk}$ süre ile yapıldı. Kaplama parametreleri ise literatür araştırma sonucu belirlendi. $\mathrm{Bu}$ sebeple, taban malzeme sicaklığ $400^{\circ} \mathrm{C}, 70 \mathrm{~W}$ taban malzeme gücü altında, proses basınc1 0,3Pa ve kaplama süresi 90dk olarak seçildi.

Tablo 1. D2 takım çeliğinin kimyasal kompozisyonu

\begin{tabular}{|c|c|}
\hline Elementler & \%wt \\
\hline $\mathrm{C}$ & 1,55 \\
\hline $\mathrm{Cr}$ & 12,0 \\
\hline $\mathrm{Mo}$ & 0,80 \\
\hline $\mathrm{V}$ & 0,90 \\
\hline $\mathrm{Mn}$ & 0,35 \\
\hline $\mathrm{Si}$ & 0,25 \\
\hline $\mathrm{Fe}$ & Denge \\
\hline
\end{tabular}

TiN filmin yapı bölge modelini ve film kalınlığını belirlemek için SEM cihazı (FEI Quanta FEG-450 SEM-EDS) kullanıldı. TiN filmin kristalografik yönlenmesi XRD cihazı $\mathrm{Cu}-\mathrm{K} \alpha$ radyasyon kaynağı kullanılarak belirlendi. Taban malzeme ile film arasındaki kritik yük (adezyon özelliği) değerini belirlemek için çizik testi yapıldı. Çizik testi, Revetester CSM Instruments çizik test cihazı kullanılarak Rockwell C elmas kalemi (120 ${ }^{\circ}$ koni, 200 mikron yarıçaplı küresel uç) ile yapıldı. Kritik kaplama yükü, $10 \mathrm{~mm} \mathrm{/}$ dakikalık bir kayma hızı ve $100 \mathrm{~N}$ / dakikalık bir yükleme hızı altında belirlendi. Ayrıca, çizik testi sonrası kritik yük değerini ve hasar türlerini belirlemek için optik mikroskop kullanıldı. Filmlerin yorulma ömrünü belirlemek için çoklu çizik testi, Revetest Scratch Tester ile kuru atmosfer koşullarında gerçekleşti. Kaplamaları çizmek için Rockwell C uç kullanıldı. Çizilme uzunluğu 3 mm çizik boyunda, yarı kritik yük değeri olan $25 \mathrm{~N}$ altında ve 500, 750 ve 1000 cycle değerlerinde iki yönlü yük (hem ileri hem geri hareketi) kullanılarak uygulandi.

\section{Bulgular}

D2 takım çeliği üzerine kaplanan TiN filmin SEM görüntüsü Şekil 1'de verilmiştir. Kaplanan TiN filmin film kalınlığı 450nm olarak ölçülmüştür. $400^{\circ} \mathrm{C}$ taban malzeme sıcaklığında kaplanan TiN filmi Yapı Bölge Modeline (SZM) göre Bölge 3 yapısı (tamamen yoğun) göstermektedir (Thornton, 1988). 


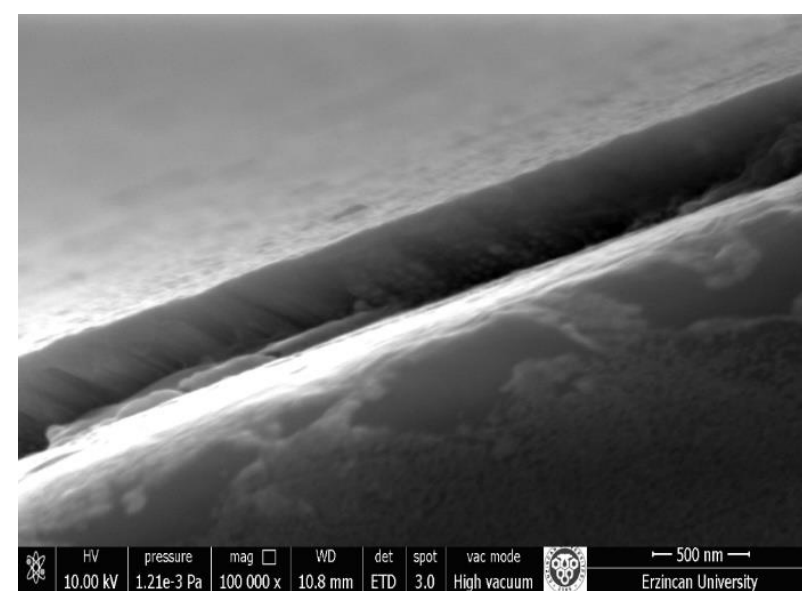

Şekil 1. TiN filmin SEM görüntüsü

D2 takım çeliği üzerine kaplanan TiN filmin

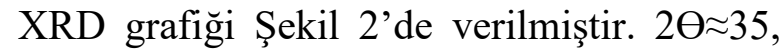
$38^{\circ}$ 'de TiN (111) fazı, $2 \Theta \approx 40^{\circ}$ 'de TiN (200) fazı, $2 \Theta \approx 64,8^{\circ}$ 'de TiN (220) faz1 ve $2 \Theta \approx 82^{\circ}$ 'de ise TiN (222) fazı belirlenmiştir (Carbonari \& Martinelli, 2001; Kim et al., 2009). XRD pikleri, TiN filmin $\mathrm{NaCl}$ tipinde kübik yapı sergileyen (111) ve (222) olmak üzere iki güçlü faza sahip tercihli oryantasyonunu göstermiştir (Samani et al., 2015).

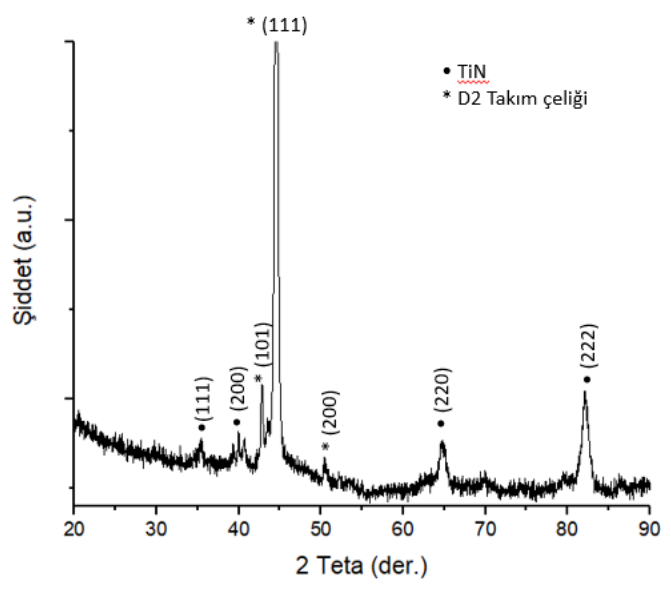

Şekil 2. TiN filmin XRD grafiği

TiN filmden çizik testi sonucu elde edilen Normal yük- sürtünme grafiği Şekil 3'de verilmiştir. Yapılan çizik testi sonucu TiN filmin kritik yük değeri $56 \mathrm{~N}$ olarak belirlenmiştir. Optik mikroskop ile çizik üzerinden alınan görüntülerde ayrıca Şekil 3'de görülmektedir. Optik mikroskop görüntüleri incelendiğinde $30 \mathrm{~N}$ 'a kadar film üzerinde herhangi bir hasar gözlemlenmemiştir. $30 \mathrm{~N}$ yükten sonra film üzerinde adeziv hasar meydana gelmiştir.

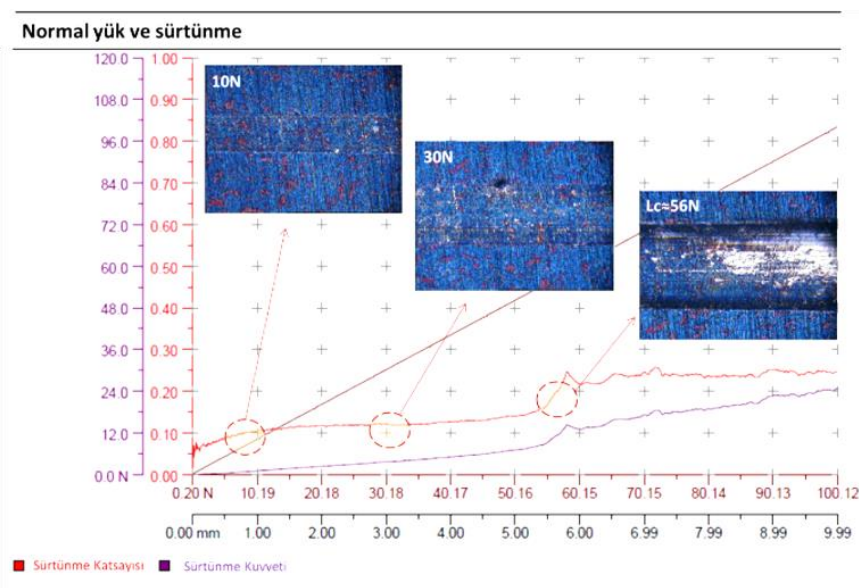

Şekil 3. TiN filmine ait çizik testi sonucu elde edilen Normal yük- sürtünme grafiği

TiN filmin yorulma ömrünü belirlemek için yapılan çoklu çizik testleri sonucu elde edilen sürtünme katsayısı $(\mu)$-mesafe grafikleri Şekil 4-Şekil 6 arasında verilmiştir. Sürtünme katsayısı $(\mu)$-mesafe grafikleri incelendiğinde artan çevrim sayısı ile yüzey pürüzlülüğünün azalmasından dolayı sürtünme katsayısı $(\mu)$ değerlerinde önemli oranda azalma meydana gelmiştir. 500, 750 ve 1000 çevrimlik çoklu çizik testi sonucu elde edilen ortalama sürtünme katsayısı $(\mu)$ değerleri sırasıyla $0,43,0,4$ ve 0,38 olarak elde edilmiştir. Sürtünme katsayısı $(\mu)$ değerleri her çevrimin ilk geçişinde (pass) en yüksek değeri sergilemiştir. Bunun sebebi ilk geçişte meydana gelen plastik deformasyondur (Efeoglu \& Arnell, 2000). Artan geçiş sayısıyla birlikte sürtünme katsayısı $(\mu)$ değerleri azalma göstermiştir. Artan geçiş sayısı ile film yüzeyinde meydana gelen yüzey pürüzlülüklerinin giderilmesi sonucu sürtünme katsayısının $\quad(\mu)$ düştüğü belirtilmiştir. 


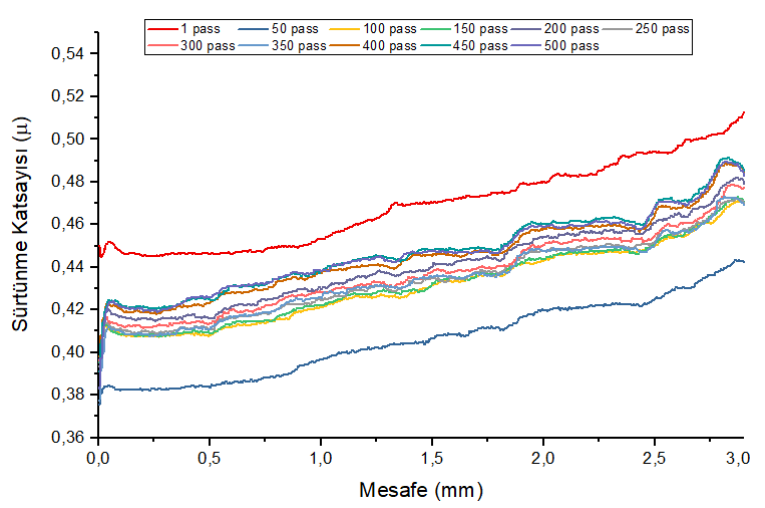

Şekil 4. TiN filminin 500 çevrimlik çoklu çizik testine ait sürtünme katsayısı $(\mu)$-mesafe grafiği

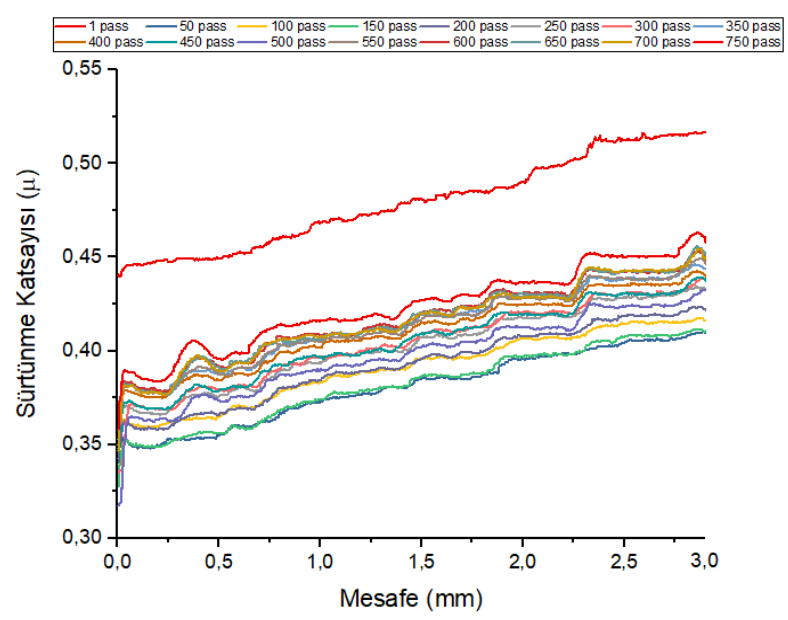

Şekil 5. TiN filminin 750 çevrimlik çoklu çizik testine ait sürtünme katsayısı $(\mu)$-mesafe grafiği

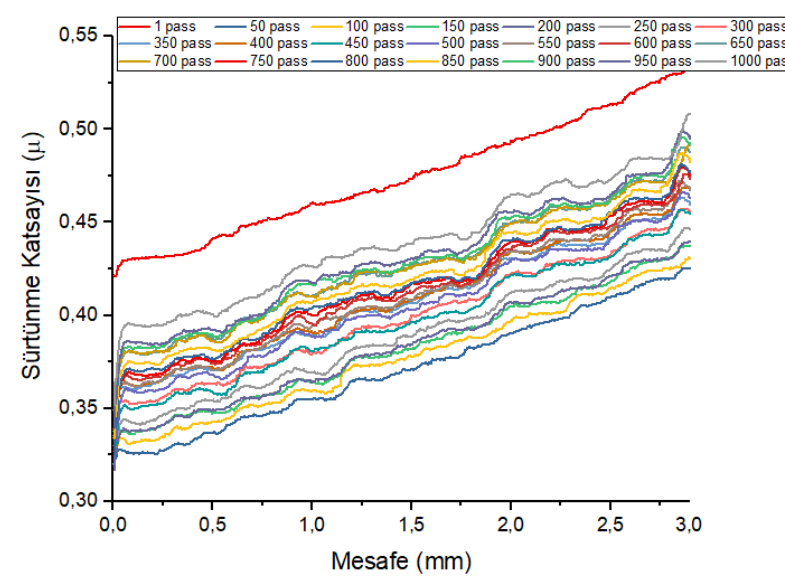

Şekil 6. TiN filminin 1000 çevrimlik çoklu çizik testine ait sürtünme katsayısı $(\mu)$-mesafe grafiği
TiN filminin 500, 750 ve 1000 çevrimlik çoklu çizik testlerinin SEM görüntüleri Şekil 7'de verilmiştir. Artan çevrim sayısı ile çizik kenarlarındaki adeziv kırılma artmıştır. Ayrıca artan çevrim ile çizik genişliğginde artış gözlemlenmiştir.

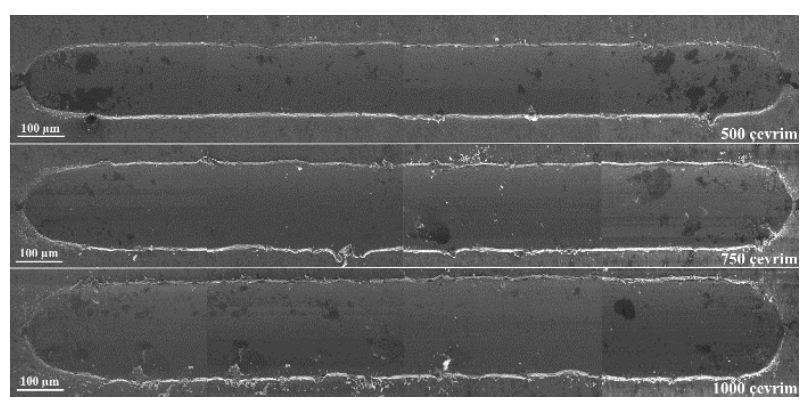

Şekil 7. TiN filminin 500, 750 ve 1000 çevrimlik çoklu çizik test görüntüleri

Çoklu çizik sonucu oluşan çiziklerin elementel oranı Tablo 2'de verilmiştir. Çevrim sayısı arttıkça taban malzemenin içeriğinde olan $\mathrm{Fe}$ oranı artmıştır. Bununla birlikte filmin içeriğinde olan $\mathrm{Ti}$ ve $\mathrm{N}$ elementlerinin miktarında ise azalma meydana gelmiştir. Ayrıca atmosfer altında yapılan deney sonucunda filmin çizilmesi ile taban malzemeye yaklaştıkça Fe elementinin oksijene karşı düşük afinitesinden dolayı $\mathrm{O}$ elementinin miktarında artma meydana gelmiştir(Baran, Sukuroglu, Efeoglu, \& Totik, 2016).

Tablo 2. Çoklu çizik sonucu oluşan çiziklerin elementel oranı

\begin{tabular}{|l|l|l|l|l|l|}
\hline & $\mathrm{N}$ & $\mathrm{Ti}$ & $\mathrm{Cr}$ & $\mathrm{Fe}$ & $\mathrm{O}$ \\
\hline $\begin{array}{l}500 \\
\text { çevrim }\end{array}$ & 7,5 & 0,32 & 10,6 & 75,08 & 6,5 \\
\hline $\begin{array}{l}750 \\
\text { çevrim }\end{array}$ & 6,91 & 0,26 & 10,53 & 75,73 & 6,57 \\
\hline $\begin{array}{l}1000 \\
\text { çevrim }\end{array}$ & 6,35 & 0,23 & 10,27 & 77,44 & 5,7 \\
\hline
\end{tabular}




\section{Sonuç ve Tartışma}

$400^{\circ} \mathrm{C}$ taban sıcaklığ 1 altında kaplanan TiN filmi ile ilgili sonuçlar aşağıdaki gibidir:

- TiN filmi SZM yapı modeline Bölge 3 (tamamen yoğun) yapı göstermiştir.

- TiN film $\mathrm{NaCl}$ tipinde kübik yap1 sergileyen (111) ve (222) kristal fazları ile tercihli büyüme göstermiştir.

- Çizik testi sonucu TiN filmin 30N'a kadar herhangi hasara uğramadığ 1 ve $56 \mathrm{~N}$ 'dan sonra filmin koptuğu gözlemlenmiştir.

- Yapılan çoklu çizik testinden sonra TiN filmlerin ömrünün 1000 çevrimden daha fazla olduğu gözlemlenmiştir. Ayrıca çizikler sonucu filmde sadece adeziv hasarların meydana geldiği ve büyük hasarların meydana gelmediği görülmüştür.

\section{Teşekkür}

$\mathrm{Bu}$ çalışmadaki destek ve yardımları için Atatürk Üniversitesi, Mühendislik Fakültesi Makine Mühendisliği Bölümü Öğretim Üyesi Sayın Prof. Dr. İhsan Efeoğlu'na ve Erzincan Binali Yıldırım Üniversitesi Mühendislik Fakültesi Makine Mühendisliği Bölümü Öğretim Üyesi Sayın Doç. Dr. Özlem Baran'a teşekkür ederim.

\section{Referanslar}

Azadi, M., Sabour Rouhaghdam, A., \& Ahangaranic, S. (2016). A Review on Titanium Nitride and Titanium Carbide Single and Multilayer Coatings Deposited by Plasma Assisted Chemical Vapor Deposition. International Journal of Engineering, 29(5),
677-687.

doi:10.5829/idosi.ije.2016.29.05b.12

Baran, Ö., Sukuroglu, E. E., Efeoglu, İ., \& Totik, Y. (2016). The investigation of adhesion and fatigue properties of $\mathrm{TiN} / \mathrm{TaN}$ multilayer coatings. Journal of Adhesion Science and Technology, 30(20), 2188-2200. doi:10.1080/01694243.2016.1176662

Bhaduri, D., Ghosh, A., Gangopadhyay, S., \& Paul, S. (2010). Effect of target frequency, bias voltage and bias frequency on microstructure and mechanical properties of pulsed DC CFUBM sputtered TiN coating. Surface \& Coatings Technology, 204(21-22), 3684-3697.

doi:10.1016/j.surfcoat.2010.04.047

Carbonari, M. J., \& Martinelli, J. R. (2001). Effects of Hot Isostatic Pressure on Titanium Nitride Films Deposited by Physical Vapor Deposition. Materials Research, 4(3), 163168.

Durusoy, H. Z., Duyar, Ö., Aydınlı, A., \& Ay, F. (2003). Influence of substrate temperature and bias voltage on the optical transmittance of TiN films. Vacuum, 70(1), 21-28. doi:10.1016/s0042-207x(02)00663-2

Efeoglu, I., \& Arnell, R. D. (2000). Multi-pass sub-critical load testing of titanium nitride coatings. Thin Solid Films, 377, 346-353. doi:10.1016/s0040-6090(00)01309-2

Ghobadi, N., Ganji, M., Luna, C., Arman, A., \& Ahmadpourian, A. (2015). Effects of substrate temperature on the properties of sputtered TiN thin films. Journal of Materials Science: Materials in Electronics, 27(3), 2800-2808. doi:10.1007/s10854-015-4093-x

Kaya, S., Yilmaz, E., Karacali, H., Cetinkaya, A. O., \& Aktag, A. (2015). Samarium oxide thin films deposited by reactive sputtering: Effects of sputtering power and substrate temperature on microstructure, morphology and electrical properties. Materials Science in Semiconductor Processing, 33, 42-48. doi:10.1016/j.mssp.2015.01.035 
Kim, S. H., Park, H., Lee, K. H., Jee, S. H., Kim, D. J., Yoon, Y. S., \& Chae, H. B. (2009). Structure and mechanical properties of titanium nitride thin films grown by reactive pulsed laser deposition. Journal of Ceramic Processing Research, 10(1), 49-53. Retrieved from <Go to ISI > ://WOS:000264403500010

Li, X. Y., Li, H. J., Wang, Z. J., Xia, H., Xiong, Z. Y., Wang, J. X., \& Yang, B. C. (2009). Effect of substrate temperature on the structural and optical properties of $\mathrm{ZnO}$ and Al-doped $\mathrm{ZnO}$ thin films prepared by $\mathrm{dc}$ magnetron sputtering. Optics Communications, 282(2), 247-252. doi:10.1016/j.optcom.2008.10.003

Ohring, M. (2001). Materials science of thin films (Second ed. ed.): Academic press.

Patsalas, p., Charitidis, C., \& Logothetidis, S. (2000). The effect of substrate temperature and biasing on the mechanical properties and structure of sputtered titanium nitride thin films. Surface and Coatings Technology, 125, 335-340.

Samani, M. K., Ding, X. Z., Khosravian, N., Amin-Ahmadi, B., Yi, Y., Chen, G., . . . Tay, B. K. (2015). Thermal conductivity of titanium nitride/titanium aluminum nitride multilayer coatings deposited by lateral rotating cathode arc. Thin Solid Films, 578, 133-138. doi:10.1016/j.tsf.2015.02.032

Sun, N., Zhou, D., Shi, S., Liu, W., Zhao, X., Liu, F., . . . Ali, F. (2019). DC substrate bias enables preparation of superior-performance TiN electrode films over a wide process window. Materials Research Bulletin, 119. doi:10.1016/j.materresbull.2019.110575

Thornton, J. A. (1988). Structure-Zone Models Of Thin Films (Vol. 0821): SPIE.

Zhang, S. Y., \& Zhu, W. G. (1993). TIN COATING OF TOOL STEELS - A REVIEW. Journal of Materials Processing Technology, 39(1-2), 165-177. doi:10.1016/0924-0136(93)90016-y 